\title{
Prevalence of Hypertension and Association with Increased Body Mass in a Semi-Urban Settlement in Nigeria
}

\author{
Abiodun M Adeoye ${ }^{1}$, Williams O Balogun' ${ }^{1}$, Adewole Adebiyi ${ }^{1}$ and Bamidele O Tayo ${ }^{2}$ \\ ${ }^{1}$ Department of Medicine, University of Ibadan, Ibadan, Nigeria \\ ${ }^{2}$ Department of Public Health Sciences, Loyola University Chicago Stritch School of Medicine, Maywood, IL, USA
}

\begin{abstract}
Introduction: Hypertension is a major cardiovascular disease and is responsible for fatal cardiovascular outcomes such as stroke, myocardial infarction, heart failure and renal failure. In Nigeria, the prevalence of hypertension and its associated complications is increasing at an alarming rate. Whereas excess weight is associated with increased rate of death from cardiovascular diseases, data on association between excess weight and hypertension in Nigerian population are sparse. In the present study we investigated the association between excess body weight and hypertension in a
\end{abstract} Nigerian semi-urban settlement.

Methods: A cross-sectional survey was carried out at the Kumapayi settlement located in the suburb of Ibadan in southwestern Nigeria. A total of 293 subjects, comprising $40 \%$ males, aged 18 years and above who consented to the study following a period of publicity and invitations to all residents of the settlement were enrolled into the study. Demographic, anthropometry and blood pressure measurements were carried out on all the subjects by trained health personnel.

Results: Mean subject age was $47.3 \pm 15.2$ years with $28.9 \%$ overweight $\left(\mathrm{BMI} 25-29 \mathrm{~kg} / \mathrm{m}^{2}\right.$ ) and $21.6 \%$ obese (BMI $\geq 30 \mathrm{~kg} / \mathrm{m}^{2}$ ). The prevalence of overweight and obesity increased with age peaking at age 40-64 years and then falling. The prevalence of hypertension (BP $\geq 140 / 90 \mathrm{mmHg}$ ) was $43.3 \%$. There was significant association between increased $\mathrm{BMI}$ and both systolic $(\mathrm{P}<0.001)$ and diastolic $(\mathrm{P}<0.002)$ pressure.

Conclusion: This study confirmed the association between overweight/ obesity and hypertension. Lifestyles changes targeted at weight reduction may help to stem the increasing trend of cardiovascular diseases in the community.

Keyword: Hypertension; Obesity; Rural; Epidemiology

\section{Introduction}

Hypertension is a major cardiovascular disease (CVD) and is responsible for fatal cardiovascular outcomes such as stroke, myocardial infarction, heart failure and renal failure [1,2]. Hypertension is highly prevalent among blacks for reasons not yet very clear [3-5]. In Nigeria, the prevalence of hypertension and its associated complications are increasing at an alarming rate [6]. The prevalence depends on the location of the study and the cut-off point for definition of hypertension. Lower prevalence was found in studies that used BP $160 / 95 \mathrm{mmHg}$ compared with BP $140 / 90 \mathrm{mmHg}$ as definition of hypertension $[7,8]$ In Meta-analysis by Ekwunife et al. [9], the prevalence ranged between $12.4 \%$ and $34.8 \%$ while study at the community in the Eastern part of Nigeria by Ejim et al. [10] showed that $46.4 \%$ of the study population had hypertension. The prevalence is higher in males compared to females.

The aetiology of hypertension is complex and it is becoming clearer that the rise in prevalence of hypertension in Nigeria cannot be completely explained by racial or genetic programming. It is of note that while studies on genetic determinants of hypertension are at various stages of conclusion worldwide including Nigeria [11-15], the role of environmental factors such as physical inactivity, obesity, and smoking cannot be ignored.

Concomitant with the increasing prevalence of hypertension is the jump in prevalence of obesity $[16,17]$. Indeed association between increased body mass and hypertension and diabetes is well established in the literature [18]. Obesity is one of the most important risk factors for hypertension and cardiovascular disease [19]. The global obesity pandemic has been attributed to increasing sedentary lifestyle and unhealthy eating habit, especially in the western developed countries
[16]. Several physiologic mechanisms including activation of the reninangiotensin-aldosterone and sympathetic nervous system, endothelial dysfunction and renal function abnormalities have been adduced for the association between obesity and hypertension [20].

Nigeria, like several other developing countries is currently experiencing an epidemiological shift from communicable to noncommunicable diseases [21]. Increasing urbanization and exposure to western lifestyles in Nigerian cities and suburbs have been implicated for the epidemiological shift [22]. In addition there are culturally conducive practices to overweight and obesity in different parts of Nigeria. However there are scanty population data on Nigerians about evidence of association between obesity and the disturbing rise in hypertension with its concomitant cardiovascular morbidity and mortality. These gaps in knowledge and the need for epidemiology data on patterns of hypertension and association with e increased body mass in Nigeria underscore the motivation for the present study in a suburban community of southwestern Nigeria. The aim of this study is therefore to assess the pattern of hypertension and determine its association with obesity in semi-urban settlement at Ibadan, Nigeria.

${ }^{*}$ Corresponding author: Abiodun M. Adeoye, Department of Medicine, University of Ibadan, Ibadan, Nigeria, Tel: 234805656 4360; E-mail: adeoyemoshood@yahoo.com

Received October 03, 2014; Accepted October 25, 2014; Published October 30 2014

Citation: Adeoye AM, Balogun WO, Adebiyi A, Tayo BO (2014) Prevalence of Hypertension and Association with Increased Body Mass in a Semi-Urban Settlement in Nigeria. J Hypertens 3: 186. doi: 10.4172/2167-1095.1000186

Copyright: @ 2014 Adeoye AM, et al. This is an open-access article distributed under the terms of the Creative Commons Attribution License, which permits unrestricted use, distribution, and reproduction in any medium, provided the original author and source are credited. 


\section{Methods}

We conducted a cross sectional study on adult females and males at least 18 years old and who were permanent residents at Kumapayi village in Egbeda local government area (ELGA), South-Western Nigeria. Kumapayi village is a semi-urban settlement located about 20 kilometers from the centre of Ibadan Metropolis. The village's total population was 2,728 and comprised of peasant farmers, petty traders, and junior government workers posted to schools and health posts in the community. The participants were randomly selected from various households after an initial brief through the community and religion leaders who were permanent residents of the settlement.

All measurements were carried out by two physicians and a nurse between 8:00 am and 10:00 am at designated community health center. Systemic blood pressure was measured using a standard Omron (HEM711DLX) blood pressure apparatus on the left arm after 5-minute rest using a cuff of appropriate size with the subject in the sitting position. Three independent blood pressure measurements were obtained with a minimum interval of one minute and the last two of three BP was used as the first may have had stress effects that settled once the subject was re-assured and became used to the procedure. Hypertension was defined as systolic blood pressure $\geq 140 \mathrm{mmHg}$ and/ or diastolic blood pressure $\geq 90 \mathrm{mmHg}$ or being on pharmacological treatment. Based on the guidelines in the Seventh Report of the Joint National Committee on Prevention, Detection, Evaluation, and Treatment of High Blood Pressure (JNC VII) [23], subjects were further classified as normal, prehypertension, stage I hypertension or stage II hypertension. Blood samples were collected under aseptic procedures from a finger puncture. Blood cholesterol level was assessed using a digital mission cholesterol meter (ACON LABORATORIES INC.USA).

Anthropometric measurements including height and weight were obtained by the nurse. Height was measured without shoes to the nearest centimeter using a ruler attached to the wall, while weight was measured to the nearest $0.1 \mathrm{~kg}$ on an electronic scale with the subject wearing light outdoor clothing without shoes or eye glasses. Body mass index (BMI) was calculated as weight in kilograms divided by the square of height in meters $\left(\mathrm{kg} / \mathrm{m}^{2}\right)$. Using the WHO criteria [24], persons with BMI of 25.0-29.9 were defined as overweight, and persons with $\mathrm{BMI} \geq 30$ were defined as obese. Ethical approval was obtained from the institutional ethical review board and informed consent was obtained from each participant.

\section{Statistical analysis}

Data was captured on excel spread sheet and then analyzed using SPSS version 17. Continuous variables were expressed as means \pm standard deviation and categorical variables as frequencies. Chisquared test was used to assess statistical independence and analysis of variance was performed to test differences in mean blood pressure in BMI classes. Stepwise (backward) multiple regression analyses were done to evaluate the independent relations of blood pressure parameters. The level of statistical significance was taken as $\mathrm{p}<0.05$.

\section{Results}

A total of 293 adults consisting of 119 (40.6\%) males and 174 (59.4\%) females, with mean age of $47.3 \pm 15.2$ years and mean BMI of $45.7 \pm 5.4$ $\mathrm{kg} / \mathrm{m}^{2}$ were studied (Table 1). Compared to males, the mean BMI and total cholesterol were higher in females. Higher proportion of females were obese $(p=0.018$, Figure 1$)$. The prevalence of prehypertension, Stage I hypertension and Stage II hypertension were 36.7\%, 19.9\% and $23.4 \%$, respectively. However, the blood pressure parameters and within hypertension classification were comparable across the gender (Table 1).

As shown in Table 2, half of the subjects were either overweight or obese with peak in obesity among subjects 40-64 years old. The relationship between systolic and diastolic blood pressure with BMI categories is presented in Table 2. There was a noticeable and statistically significant association between higher systolic or diastolic blood pressure with higher BMI status. Similarly, we observed moderately statistically significant association $(\mathrm{p}=0.038)$ between BMI and hypertension classifications (Table 2) among the subjects. Also there was significant linear relationship between weight and blood pressure as shown in Figure 2.

\section{Discussion}

In this study we report that $36.7 \%$ and $43.3 \%$ of the study population were pre-hypertensives and hypertensives, respectively. Obese and overweight subjects constituted $28.9 \%$ and $21.6 \%$, respectively, of the total population. Among the hypertensives, $19.9 \%$ were Stage I, and 23.4\% Stage II. Over weight and obesity increased with age peaking at age 40-64 years and then showing decline thereafter. The prevalence of hypertension defined as blood pressure equal to or greater than $140 / 90 \mathrm{mmHg}$, was noted in $43.3 \%$ of our subjects. This is higher than the prevalence of less than $10 \%$ earlier reported in Ghana and Nigeria community. In a previous nationwide study [1] carried out over 15 years ago in Nigeria, the prevalence of hypertension was $7 \%$ in the rural population and $20 \%$ in the urban settlement; these Figures may not represent the current prevalence of hypertension in a country which has been undergoing rapid urbanization with accompanying increasing overweight [17]. The low prevalence reported in previous studies might have resulted from high cut-off point of $160 / 95 \mathrm{mmHg}$ used in the Nigeria survey. However the rising trend of hypertension in rural communities has been well documented. Findings by Escalona et al. [19] and Amoah et al. [2] from different communities in Ghana noted prevalence of $26.8 \%$ and $28 \%$, respectively. The findings in current study are similar to those reported for Enugu, the Eastern part of Nigeria where Ejim et al. [10] reported the prevalence of $46.4 \%$ and $30 \%$ for hypertension and obesity respectively. In contrast, Oladapo et al. [25] found $20.8 \%$ in their rural population being hypertensive. This difference in prevalence reported in the study and that reported in the present study may be due to the higher proportion of obesity in our subjects, and the fact that participants in Ejim's study were elderly. Of concern is additional high prevalence of prehypertension of $36.7 \%$ which is similar to $39.2 \%$ found in Oladapo's study. Prehypertension is an indicator of a future cardiovascular burden. Review of prospective studies by Huang et al. [26] have shown that after controlling for multiple cardiovascular risk factors, prehypertension is significantly associated with CVD mortality and the risk for stroke mortality is higher than coronary heart disease mortality [27]. Early adoption of life style modification such as weight reduction, increased physical activities and increased consumption of fruits and vegetables, with a reduction in sodium intake could stem the tide of cardiovascular morbidity and mortality in the community

The rising trend of adiposity is a global health concern. Obesity is an independent risk factor for cardiovascular morbidity and mortality $[28,29]$. Similar to the finding in Ejim et al., $28.9 \%$ and $21.6 \%$ of our study population were obese and overweight respectively. Oladapo et al. [25] had earlier reported a prevalence of obesity of about $4 \%$ from a rural community in the same local government area where 
Citation:Adeoye AM, Balogun WO, Adebiyi A, Tayo BO (2014) Prevalence of Hypertension and Association with Increased Body Mass in a SemiUrban Settlement in Nigeria. J Hypertens 3: 186. doi:10.4172/2167-1095.1000186

Page 3 of 5

\begin{tabular}{|c|c|c|c|c|}
\hline & Men $(n=119)$ & Women $(n=174)$ & Total $(n=293)$ & $\mathrm{p}$-value \\
\hline Age(years) & $49.92 \pm 14.9$ & $48.20 \pm 14.8$ & $47.69 \pm 14.8$ & 0.485 \\
\hline Height $(m)$ & $1.67 \pm 0.1$ & $1.56 \pm 0.1$ & $1.6 \pm 0.1$ & 0.0001 \\
\hline Weight(kg) & $68.56 \pm 12.8$ & $64.81 \pm 15.7$ & $66.34 \pm 14.7$ & 0.032 \\
\hline Body mass index $\left(\mathrm{kg} / \mathrm{m}^{2}\right)$ & $24.56 \pm 4.6$ & $26.64 \pm 5.8$ & $25.80 \pm 5.4$ & 0.001 \\
\hline Systolic blood pressure $(\mathrm{mmHg})$ & $136.97 \pm 25.1$ & $136.80 \pm 31.3$ & $136.46 \pm 28.9$ & 0.812 \\
\hline Diastolic Blood Pressure $(\mathrm{mmHg})$ & $83.67 \pm 14.4$ & $83.32 \pm 15.8$ & $83.46 \pm 15.2$ & 0.851 \\
\hline Pulse Pressure & $47.76 \pm 14.6$ & $49.93 \pm 20.1$ & $49.08 \pm 18.1$ & 0.387 \\
\hline Mean Arterial Pressure & $96.89 \pm 13.2$ & $96.21 \pm 20.9$ & $96.47 \pm 18.2$ & 0806 \\
\hline Total Cholesterol(mg/dl) & $159.42 \pm 47.3$ & $178.48 \pm 49.7$ & $169.94 \pm 49.4$ & 0.037 \\
\hline Hypertension group & & & & 0.257 \\
\hline Normal (\%) & 15.4 & 23.1 & 19.9 & \\
\hline Prehypertension (\%) & 40.2 & 34.3 & 36.7 & \\
\hline Stage I hypertension (\%) & 23.1 & 17.8 & 19.9 & \\
\hline Stage II hypertension (\%) & 21.4 & 24.9 & 23.4 & \\
\hline
\end{tabular}

Table 1: General characteristics of subjects

\begin{tabular}{|c|c|c|c|}
\hline & Normal BMI & Overweight & Obese \\
\hline Systolic BP $(\mathrm{mmHg})$ & $131.6 \pm 25.1$ & $136.5 \pm 29.2$ & $148.4 \pm 34.1$ \\
\hline Diastolic BP $(\mathrm{mmHg})$ & $80.5 \pm 13.9$ & $85.1 \pm 15.8$ & $88.4 \pm 15.7$ \\
\hline Age group & & & 0.001 \\
\hline Young (<40yrs) & $50(17.2)$ & $19(6.5)$ & 0.002 \\
\hline Middle-aged (40-64 yrs) & $65(22.3)$ & $56(19.2)$ & $46(15.8)$ \\
\hline Elderly (>65yrs) & $29(10.0)$ & $9(3.1)$ & $6(2.1)$ \\
\hline Hypertension class & $31(11.2)$ & $18(6.5)$ & \\
\hline Normal & $56(20.3)$ & $23(8.3)$ & \\
\hline Pre-hypertension & $29(10.5)$ & $14(5.1)$ & $23(1.8)$ \\
\hline Stage 1 hypertension & $22(8.0)$ & $23(8.3)$ & $13(4.7)$ \\
\hline Stage 2 hypertension & & & \\
\hline
\end{tabular}

Table 2: Relations of Body Mass Index groupings

our study was carried out. The higher prevalence of obesity in our population could be due to relatively higher exposure to westernized urban lifestyle compared to the core rural setting in Oladapo's study. Although our study did not assess the level of physical activities and dietary intake, the impact of urbanization on development of obesity and metabolic syndrome has been well reported in literature [30]. The prevalence of $23 \%$ reported for obesity by Jackson et al. [31] in rural US was much higher than Oladapo's finding, again underscoring the role of environment in the development of increased body mass. This is similar to what was reported by Varghese et al. [32].

The current study showed a linear relationship between increase weight and blood pressure levels. Data from rural communities of India and parts of Indonesia [33-36] have shown increasing rate of obese hypertensive which is similar to the findings in our current study which signifies an epidemic shift to non-communicable diseases among developing countries. This is evidently resulting from changing lifestyles and dietary habits especially among the middle and high social class persons. Among other non-pharmacological management of obese Hypertensives, Andrews et al. [37] showed that weight reduction was more effective. Obesity remains a major cardiovascular risk factor for high blood pressure that must be addressed holistically in the prevention and management of hypertension associated morbidity and mortality.

\section{Limitations to the Study}

Confirmation of elevated blood pressure on another occasion is ideal to diagnose clinical hypertension rather than just taking average of 2 or 3 readings at single visit as done in the current study. However, recording average of 2 or 3 blood pressure measurements at a point in time has been reported in epidemiological studies [36]. Furthermore, assessment of general adiposity was done in our study. It would have been interesting to explore association of visceral adiposity with hypertension. Lastly, although our study population could be said to be representative of the community, the same may not be true for the entire country in view of differences in body composition and cultural practices in a multi-ethnic country like Nigeria and most importantly since data on lifestyle factors were not collected which could have been helpful in interpreting the findings of an epidemiological survey.

\section{Conclusion}

Our study confirmed increased prevalence of hypertension and association between overweight/obesity and hypertension in a Yoruba community of Nigeria. Lifestyle changes targeted at weight reduction

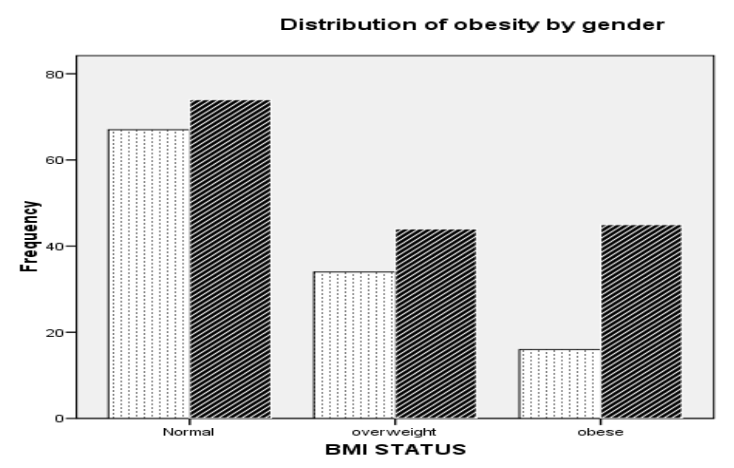

Figure 1: Distribution of obesity by gender; $p$ value $=0.018$ 
Citation:Adeoye AM, Balogun WO, Adebiyi A, Tayo BO (2014) Prevalence of Hypertension and Association with Increased Body Mass in a SemiUrban Settlement in Nigeria. J Hypertens 3: 186. doi:10.4172/2167-1095.1000186
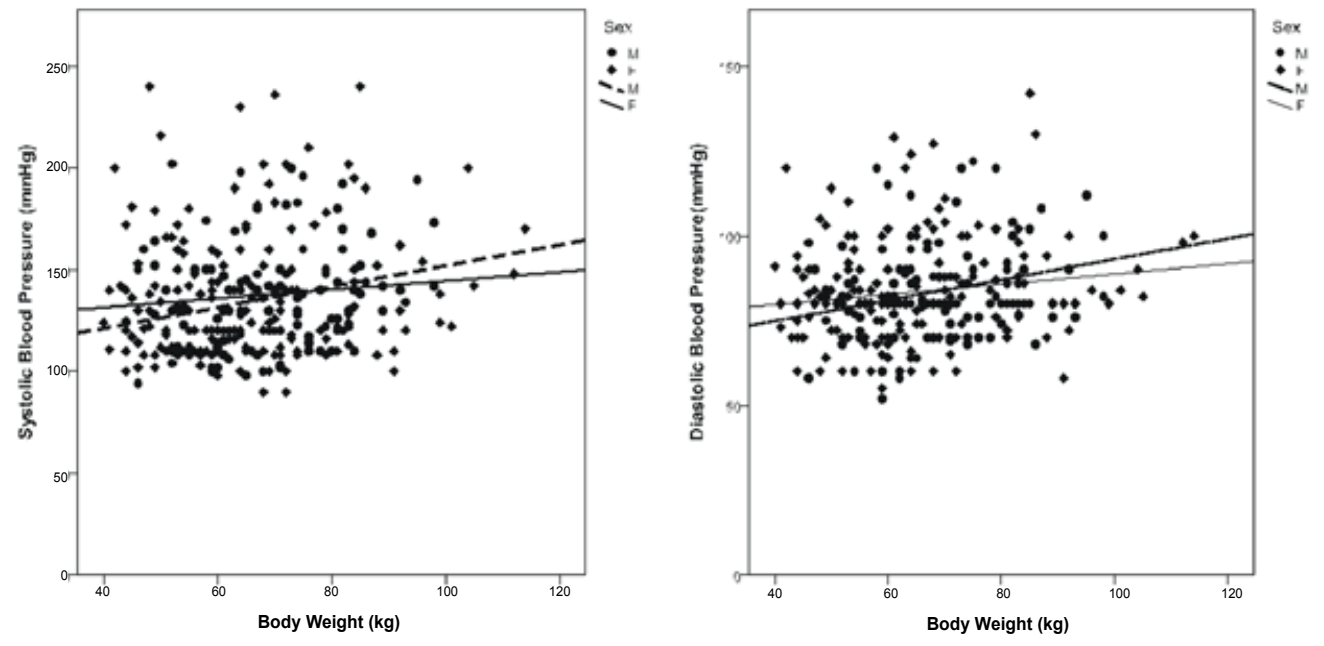

Figure 2: Scatter diagrams and regression lines of blood pressures (systolic and diastolic) and body weight

will help to stem the increasing trend of cardiovascular diseases in this population. This may give credence to the advocacy by the World Heart Federation to reduce cardiovascular related death by $25 \%$ in 2025 . Longitudinal data may provide stronger evidence and better allow for categorization of the association between obesity and hypertension in this population.

\section{References}

1. Akinkugbe $\mathrm{OO}$ (2005) Current epidemiology of hypertension in Nigeria. Archives of Ibadan Medicine 1: 3-5.

2. Amoah AG (2003) Hypertension in Ghana: a cross-sectional community prevalence study in greater Accra. Ethn Dis 13: 310-315.

3. Cooper R, Rotimi C (1997) Hypertension in blacks. Am J Hypertens 10: 804-812.

4. Gibson GS, Gibbons A (1982) Hypertension Among Blacks. Hypertension 4: 3-51.

5. Saunders E (1991) Hypertension in blacks. Prim Care 18: 607-622.

6. Akpa M, Mato C (2008) Obesity in Nigeria: current trends and management. Nigerian Medical Practitioner 54: 11-15.

7. Adedoyin RA, Mbada CE, Balogun MO, Martins T, Adebayo RA, et al. (2008) Prevalence and pattern of hypertension in a semiurban community in Nigeria. Eur J Cardiovasc Prev Rehabil 15: 683-687.

8. Alikor CA, Emem-Chioma PC, Odia OJ (2013) Hypertension in a Rural Community in Rivers State, Niger Delta Region of Nigeria: Prevalence and Risk Factors. Nigerian Health Journal 13:18-25.

9. Obinna IE, Cletus NA (2011) A meta analysis of prevalence rate of hypertension in Nigerian populations. Journal of Public Health and epidemiology 3: 604-607.

10. Ejim EC, Okafor Cl, Emehel A, Mbah AU, Onyia U, et al. (2011) Prevalence of cardiovascular risk factors in the middle-aged and elderly population of a nigerian rural community. J Trop Med 2011: 308687.

11. Franceschini N, Fox E, Zhang Z, Edwards TL, Nalls MA, et al. (2013) Genomewide association analysis of blood-pressure traits in African-ancestry individuals reveals common associated genes in African and non-African populations. Am J Hum Genet 93: 545-554.

12. Franceschini N, Le TH (2014) Genetics of hypertension: discoveries from the bench to human populations. Am J Physiol Renal Physiol 306: F1-1F11.

13. Reder NP, Tayo BO, Salako B, Ogunniyi A, Adeyemo A, et al. (2012) Adrenergic alpha-1 pathway is associated with hypertension among Nigerians in a pathway-focused analysis. PLoS One 7: e37145

14. Newton-Cheh C, Johnson T, Gateva V, Tobin MD, Bochud M, et al. (2009) Genome-wide association study identifies eight loci associated with blood pressure. Nat Genet 41: 666-676.

15. Levy D, Ehret GB, Rice K, Verwoert GC, Launer LJ, et al. (2009) Genome- wide association study of blood pressure and hypertension. Nature genetics 41: 677-687.

16. Kennedy G, Nantel G, Shetty P; Food and Agriculture Organization of the United Nations (2004) Globalization of food systems in developing countries: impact on food security and nutrition. FAO Food Nutr Pap 83: 1-300.

17. Akintunde AA, Akinwusi PO, Adebayo RA, Ogunyemi S, Opadijo OG (2010) Burden of obesity in essential hypertension: pattern and prevalence. Niger $J$ Clin Pract 13: 399-402.

18. Cooper R, Rotimi C, Ataman S, McGee D, Osotimehin B, et al. (1997) The prevalence of hypertension in seven populations of west African origin. Am J Public Health 87: 160-168.

19. Escalona A, Sarfo M, Kudua L (2006) Obesity and systemic hypertension in Accra communities. Ghana Medical Journal 38: 145-148.

20. Sironi AM, Gastaldelli A, Mari A, Ciociaro D, Positano V, et al. (2004) Viscera fat in hypertension: influence on insulin resistance and beta-cell function. Hypertension 44: 127-133.

21. [No authors listed] (1996) Hypertension control. Report of a WHO Expert Committee. World Health Organ Tech Rep Ser 862: 1-83.

22. Hall JE (2003) The kidney, hypertension, and obesity. Hypertension 41: 625-633.

23. Chobanian AV, Bakris GL, Black HR, Cushman WC, Green LA, et al. (2003) Seventh report of the Joint National Committee on Prevention, Detection, Evaluation, and Treatment of High Blood Pressure. Hypertension 42: 1206-1252.

24. [No authors listed] (1995) Physical status: the use and interpretation of anthropometry. Report of a WHO Expert Committee. World Health Organ Tech Rep Ser 854: 1-452.

25. Oladapo O, Salako L, Sodiq O, Shoyinka K, Adedapo K, et al. (2010) A prevalence of cardiometabolic risk factors among a rural Yoruba south-western Nigerian population: a population-based survey. Cardiovasc J Afr 21: 26-31.

26. Huang Y, Su L, Cai X2, Mai W3, Wang S, et al. (2014) Association of all-cause and cardiovascular mortality with prehypertension: a meta-analysis. Am Heart J 167: 160-168.

27. Huang Y, Cai X, Li Y, Su L, Mai W, et al. (2014) Prehypertension and the risk of stroke: a meta-analysis. Neurology 82: 1153-1161.

28. Poirier P, Giles TD, Bray GA, Hong Y, Stern JS, et al. (2006) Obesity and cardiovascular disease: pathophysiology, evaluation, and effect of weight loss an update of the 1997 American Heart Association Scientific statement on obesity and heart disease from the obesity committee of the council on nutrition, physical activity, and metabolism. Circulation 113: 898-918.

29. Hubert HB, Feinleib M, McNamara PM, Castelli WP (1983) Obesity as an independent risk factor for cardiovascular disease: a 26-year follow-up of participants in the Framingham Heart Study. Circulation 67: 968-977. 
Citation:Adeoye AM, Balogun WO, Adebiyi A, Tayo BO (2014) Prevalence of Hypertension and Association with Increased Body Mass in a SemiUrban Settlement in Nigeria. J Hypertens 3: 186. doi:10.4172/2167-1095.1000186

30. Lopez AD, Mathers CD, Ezzati M, Jamison DT, Murray CJ (2001) Global and regional burden of disease and risk factors, 2001: systematic analysis of population health data. The Lancet 367: 1747-1757.

31. Jackson JE, Doescher MP, Jerant AF, Hart LG (2005) A national study of obesity prevalence and trends by type of rural county. J Rural Health 21: 140-148.

32. Varghese RT, Vijayakumar K (2008) Prevalence pattern of obesity across different age groups in a rural setting in Kerala. Calicut Medical Journal 6: e3.

33. Rahmouni K, Correia ML, Haynes WG, Mark AL (2005) Obesity-associated hypertension: new insights into mechanisms. Hypertension 45: 9-14.
34. Misra A, Khurana $L$ (2008) Obesity and the metabolic syndrome in developing countries. J Clin Endocrinol Metab 93: S9-30.

35. Ng N, Stenlund H, Bonita R, Hakimi M, Wall S, et al. (2006) Preventable risk factors for noncommunicable diseases in rural Indonesia: prevalence study using WHO STEPS approach. Bull World Health Organ 84: 305-313.

36. Singh RB, Sharma JP, Rastogi V, Niaz MA, Singh NK (1997) Prevalence and determinants of hypertension in the Indian social class and heart survey. J Hum Hypertens 11: 51-56.

37. Andrews G, MacMahon SW, Austin A, Byrne DG (1982) Hypertension: comparison of drug and non-drug treatments. Br Med J (Clin Res Ed) 284: 1523-1526. 